\title{
Enterprise Risk Scorecard Application on Indonesian State-Owned Enterprises in Shipping Companies
}

\author{
Christian Samuel*, Aries Heru Prasetyo \\ Sekolah Tinggi Manajemen PPM \\ Jakarta, Indonesia \\ *csamue193@gmail.com
}

\begin{abstract}
Enterprise Risk Scorecard (ERS) essentially is a Balanced Scorecard (BSC) combined with risk management. This experiment's objective is to find out how ERS is applied to Indonesian SOEs in shipping companies. BSC focuses on objectives of company's performance while ERS focuses on risk treatment that is perceived to affect the KPI achievement process. By 2018, Indonesia only had total of 19 ships and 226,948 deadweight tons and the number of ships which operated by SOEs is declining since 2014 and this affect the deadweight tons which also is declining. According to Indonesian Ministry of State-Owned Enterprise (SOE) Regulation for Good Corporate Governance (GCG) Application, risk management is an integral part of GCG by developing and applying risk management program as a whole strategic activity. This declining situation and the compliance due to Regulation of Indonesian Ministry of SOE for GCG then become the reason risk management must be applied in SOEs. Risk management in Indonesia is applied in two ways and they are done by paradigm of risk management and reward and punishment. Qualitative case study is used in this research with inductive approach and data is collected by focus group discussion. The results are ERS application for company A and company $B$ is adopted by paradigm model while for company C, ERS is applied by reward and punishment. ERS helps each company to apply risk management for the whole company to achieve their stated KPI by combining risk management into the BSC. By applying ERS, those companies will have a higher probability to achieve their own strategic KPI.
\end{abstract}

Keywords-balanced scorecard, enterprise risk scorecard, Indonesia, risk management, state-owned enterprise

\section{INTRODUCTION}

Balanced Scorecard (BSC) is a framework which is used to describe initiatives that affect company's performance to the business strategy. BSC involves vision and mission of the company to be transformed into a set of comprehensive plans for system management and strategic framework. BSC emphasize on achieving financial goals by involving performance trigger to achieve those goals. 4 perspectives are used in BSC and they are financial, customer, internal process, and learning and growth. BSC helps company to have a clearer image of the results while keep monitoring the assets' growth for the future. Financial and non-financial plans must be an integral part of the information system for the whole employees. BSC is done in top-down approach starting from the vision and mission to the initiative strategies. Initiatives must be balanced between external stakeholders and internal stakeholders. Initiatives must also be balanced between result from the past and triggers to improve performance in the future [1].
Alignment is needed in formulating BSC to create synergy for the company. Alignment is reviewed on the process of creating value to the stakeholders through improving customer relationship which supported by a good internal process. This concept is started with 4 perspectives in BSC to determine the value proposition for each perspective. In financial perspective, the value proposition is the expectation of shareholders for the financial performance. In customer perspective, the value proposition is how company create value for the customer to achieve financial goals. In internal process perspective, the value proposition is the process which should be a competitive advantage to fulfil customer's and shareholders' expectation. In learning and growth perspective, the value proposition is how company align intangible assets such as human resources, system, and culture to improve key process. Value proposition from all 4 perspective form a synergy which align with the company's goal. It can be concluded that BSC is a framework to measure company's performance with initiative strategies to create synergy and alignment with one and another to achieve company's goal [2].

Meanwhile, Enterprise Risk Management (ERM) is an integrated and comprehensive framework to manage key risks with purposes to achieve company's goals, minimize unexpected revenue volatility, and maximize corporate value. There are 3 benefits from ERM which are improving organization effectiveness, improving risk reporting mechanism, and improving business performance. Organization effectiveness is improved by creating new unit specialized in risk or risk manager. ERM application needs a good top-down coordination which will make the company perform more efficient. Integrated team will be ready to face risk and can gain advantage from the interconnectedness of the risks that will occur. In risk reporting, ERM decides the priority of the risk that should be treated and reported to the top management. Business performance is improved through the advantage from ERM when making decision in capital allocation, product development and price calculation, and merger and acquisition. The results of ERM are decrease of loss, decrease of revenue volatility, increase of revenue, and increase of value to shareholders. Company will also understand the real risk and return of the business [3].

Enterprise Risk Scorecard (ERS) is a BSC integrated with risk measurement. The differences between measurement in company's performance and company's risk become obstacle when integrating risk into BSC. Risk measurement and performance measurement usually are done by different person from different division. On the practice, ERS is made separately from BSC yet both of them still are integrated with 
the company's overall strategy. Scorecard framework is able to help creating and communicating risk management activities. ERS is made based on BSC with 4 perspectives. In financial risk perspective, risk generally based on financial statement analysis which contain of liquidity ratio, solvability ratio, profitability ratio, and efficiency ratio. In customer risk perspective, risk generally based on marketing activities and customer relationships. In internal process risk perspective, risk generally based on activities involved in executing business strategies from the BSC. Several risks that usually reviewed from internal process perspective are technological risk, human resources risk, process risk, and organizational risk. In learning and growth risk perspective, learning risk is generally based on how training and development effectively affect productivity. ERS will be used to measure risks that will occur when executing strategies from BSC [4].

BSC and ERM have several similarities. Both of them focus on the strategy to achieve company's goals, overall approach, emphasize in interconnectedness and integration, top-down approach, consistency and accountability, and emphasize in continuity. The process of integrating BSC into ERM will broaden the scope of the strategy by connecting risk management with strategic performance explicitly. This integration process will also strengthen BSC process that will make the executers aware to risk and need to treat the risks so this will help learning and growth process. Reducing or getting rid of risks exposure will also improve internal business process. This will have positive impacts on customer satisfaction and financial performance improvement. At last, BSC will focus on measuring performance in achieving strategic goals while ERM emphasizes on treating positive and negative factors that affect the goals achieving process. Both of them will become a natural and apt combination in achieving company's success [5].

Research for ERM adoption factor by Paape and Speklé in 2012 showed that regulatory environment, internal factors, ownership structure, and firm and industry-related characteristic influence the ERM implementation [6]. Internal factors are described as the presence of a CRO and audit committee which can influence management to implement ERM. Another research for ERM adoption by Altuntaz, BerryStölzle and Hoyt in 2011 showed that top management's decision to adopt ERM is influenced by managerial career concern [7]. Top management realize that there is a consequence of getting fired if the firm doesn't perform well enough. Research by Hussin, Yazid, and Razali in 2012 showed that commitment and support from top management strongly helps the implementation of risk management [8]. Top management's concern on risk management will helps to promote risk culture in the governance. This research also showed that the availability of risk management framework and initiatives provides management with motivation and confidence to manage risks effectively. Oulasvirta and Anttiroiko's research in 2017 showed that comprehensive risk management is not used in the Finland's local government if it's not obligatory [9]. Since SOE is closely related to government, the government culture somehow affects the SOE corporate culture.
By 2018, Indonesia only had 3 SOEs in shipping industry with total of 19 ships and 226,948 deadweight tons. The number of ships which operated by SOEs is declining since 2014 and this affect the deadweight tons which also is declining. According to Indonesian Ministry of State-Owned Enterprise (SOE) Regulation for Good Corporate Governance (GCG) Application, risk management is an integral part of GCG by developing and applying risk management program as a whole strategic activity. This declining situation and the compliance due to Regulation of Indonesian Ministry of SOE for GCG then become the reason risk management must be applied in SOEs. In this research, risk management is applied in form of ERS therefore the purpose of this research is to find out how ERS is applied in Indonesian SOEs in shipping industry. This research proposes two models of ERS application in Indonesian SOEs in shipping industry. Different industry or private sector may have a different model of ERS application but they're not the focus of this research. This research is the first to be done in Indonesia since ERS is still a new approach of applying ERM in Indonesia.

\section{METHODS}

Observation is done from Q1 to Q2 2019 on 3 Indonesian shipping SOEs. Qualitative case study is used in this research. Inductive approach is used and data was collected by focus group discussion (FGD) with BoD of each company.

\section{RESULTS}

ERS is adopted in company A and B by paradigm model while company $\mathrm{C}$ adopted risk management by reward and punishment model. Those companies successfully adopted ERS during observation period with both models and are perceived to continue managing their risks with the ERS.

\section{DISCUSSION}

ERS is used as a form of risk management for a company's long-term plan (5 years ahead of plan) which already in a form of BSC. Risk identification is done for each strategy initiative to find risks that are related to the initiatives. Risk analysis than is done for each risk to define risk treatment and all the risks, before and after risk treatment, are mapped into a risk matrix. Risks that considered high then get further analysed to define the key risk indicator and response plan if the key risk indicator happens in the future. Theory of Planned Behavior (TPB) is used to explain the reason of the results. The behavior goal is to apply ERS and is applied to both models. The framework as explained in TPB for the results for Reward and Punishment Model is shown in Figure 1. 


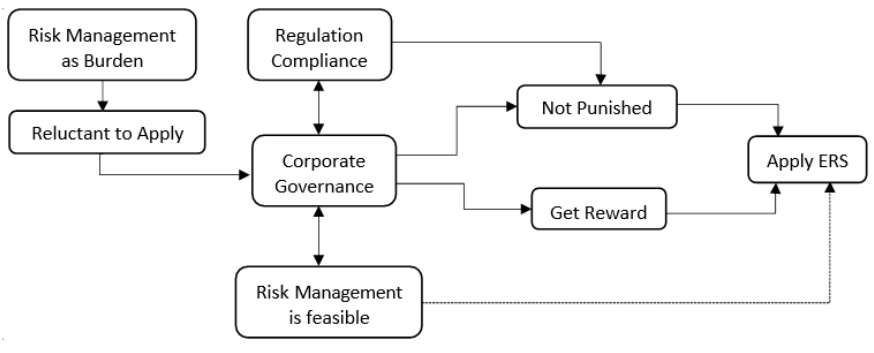

Fig. 1. Framework of reward and punishment model.

In reward and punishment model, reluctance to apply risk management as the attitude toward the behaviour because management consider risk management as burden, sometimes it means costly and ineffective. Compliance to regulation by Indonesian Ministry of SOE and corporate governance from BoD become the subjective norms and perception that risk management is feasible become the perceived behavioural control. The regulation insists the $\mathrm{BoD}$ to integrate risk management into their governance and the BoD also perceived risk management is something that is feasible to be applied. Therefore, management have two intentions of applying risk management which are desire to get reward and fear for being punished by stakeholders. The most common punishment that the management fear is getting fired by the BoD and the loss of trust from the stakeholders. The loss of trust from stakeholders can affect the business process itself in a negative way. Furthermore, it will become an obstacle for company to achieve its stated KPI. As for the reward, promotion is the highest reward that people in management can get. Sometimes, the reward can also be in a form of bonus or incentive and good reputation in front of the superiors. These intentions then become triggers and reasons for management to apply risk management in form of ERS. These intentions might not be the only intentions for management to apply risk management. Management's desire to achieve the KPI may also become the intention but the role of this intention isn't significant compared to the other two based on result of the FGD (Figure 2).

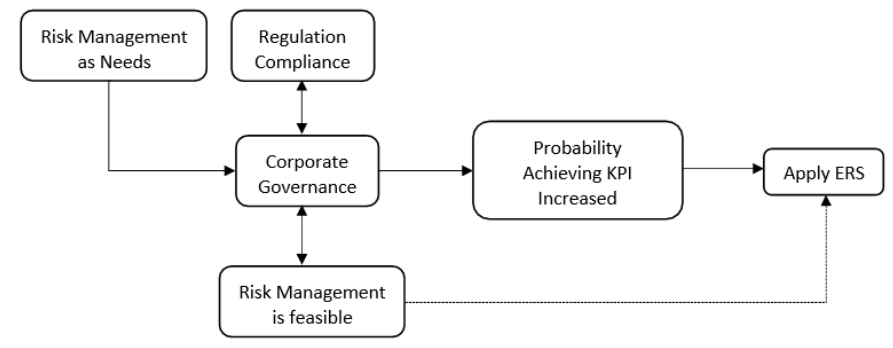

Fig. 2. Framework of paradigm model.

On the other hand, paradigm model considers risk management as an internal need. This attitude towards behavior furthermore perceived to become the company's strength. Similar with the reward and punishment model, compliance to regulation by Indonesian Ministry of SOE and corporate governance from BoD become the subjective norms and perception that risk management is feasible become the perceived behavioral control. The synergy by all of these elements then build an intention to apply risk management which is to increase the probability of achieving KPI.

These are some explanation of the characteristics of each company. All companies were established around 1950 to 1960 so these companies had been operated for a long time. Only one from three companies is already in a stable condition with Company $\mathrm{A}$ as the most established. There are also some differences in top management structure for each company. Company A has the most complex structure among these three. Company A has CEO, CHRO (also managing general affairs), $\mathrm{CFO}$, and 3 Chief Officer for each business line (shipping and marine toll, passenger transportation, and fleet). On the other hand, Company $\mathrm{B}$ and $\mathrm{C}$ have quite similar top management structure which contains of $\mathrm{CEO}, \mathrm{CFO}$, and COO. Company $\mathrm{A}$ and $\mathrm{B}$ are holding companies while Company $\mathrm{C}$ is a subsidiary of another SOE in energy industry. Only company A has the business line in passenger transportation but in this research, we are focusing on their shipping business line. The main commodity to be shipped among these companies is coal but there is also some other commodity that are shipped by each company. All companies have already applied risk management so applying ERS is their next step in applying risk management.

Compliance to Regulation of Indonesian Ministry of SOE represents the result from Paape and Speklé's and Oulasvitra and Anttiroiko's research [6].

Complying to the regulation become something obligatory and the regulation insists the companies to apply risk management. In reward and punishment model, it represents the result from Altuntas, Berry-Stölzle, and Hoyt's research [7]. The fear of being punished, especially the fear of getting fired is a part of managerial career concern. Furthermore, in this research, management's fear of getting fired is not just based on achieving KPI but also based on hierarchical organization structure. Management tends to obey their superordinate's decision directly just to keep their career safe. Corporate governance represents the result from Hussin, Yazid, and Razali's research. Top management's concern and commitment on risk management become a great contribution to the adoption process [8]. Top management fully supports the ERS adoption process by actively looking for further information related to how to make the ERS and how to use it effectively. At the end of the research, having ERS makes the top management to gain confidence in applying risk management and in achieving the KPI. They are convinced that each initiative strategies that they've been decided is already strengthened by risk management therefore the probability of achieving those KPI is higher than before.

\section{CONCLUSION}

There are 2 adaptation models of Enterprise Risk Scorecard for 3 Indonesian SOEs in shipping industry. Reward and punishment model show that pursuing reward and avoiding punishment insist management to apply ERS while paradigm model shows that management themselves voluntarily apply ERS. Those models are explained with TPB. Company A and $\mathrm{B}$ adopt the paradigm model while company $\mathrm{C}$ adopt the reward and punishment model. For further study, this kind of 
research can be done for Indonesia's shipping companies of private sector. Therefore, the ERS adoption profile for all shipping companies in Indonesia can be mapped.

\section{REFERENCES}

[1] R.S. Kaplan and D.P. Norton, The Balanced Scorecard: Translating Strategy into Action. Boston: President and Fellows of Harvard College, 1996.

[2] R.S. Kaplan and D.P. Norton, Alignment: Using the Balanced Scorecard to Create Corporate Synergies. Boston: Harvard Business School Publishing Corporation, 2006.

[3] J. Lam, Enterprise Risk Management: From Incentives to Controls (2nd Edition). Hoboken, NJ: Wiley, 2014.

[4] J. Calandro, and S. Lane, "Insights from the Balanced Scorecard: An Introduction to the Enterprise Risk Scorecard," Measuring Business Excellence, vol. 10, no. 3, pp. 31-40, 2006.
[5] M.S. Beasley, A. Chen, K. Nunez, and L. Wright, "Working Hand in Hand: Balanced Scorecards and Enterprise Risk Management," Strategic Finance, pp. 49-55, 2006.

[6] L. Paape and R.F. Speklé, "The Adoption and Design of Enterprise Risk Management Practices: An Empirical Study," European Accounting Review, vol. 21, no. 3, pp. 533-564, 2012.

[7] M. Altuntas, T.T. Berry-Stölzle, and R.E. Hoyt, "Dynamic Determinants of Enterprise Risk Management Adoption in the Property-Liability Insurance Industry: Evidence from Germany," Journal of Risk Management, vol. 123, no, 17, pp. 1234-1244, 2011.

[8] M.R. Hussin, A.S. Yazid, and A.R. Razali, "Enterprise-Wide Risk Management (EWRM) as A Value-added Tool in Enhancing the Economic Value of Business Enterprisesm," Int Bus Res, vol. 5, no. 1, pp. 83-98, 2012.

[9] L. Oulasvirta, and A. Anttiroiko, "Adoption of Comprehensive Risk Management in Local Government," Local Government Studies, vol. 43, no. 3, pp. 451-474, 2017. 